\title{
BEHAVIORAL SCIENTOCRACY: ONE LAST WORD
}

\author{
Jeffrey L. Edleson \\ University of Wisconsin
}

Despite the immediately preceding statements I find no evidence to convince me that, as Nicolaus has previously stated, "it is within the competence of a scientific analysis to make clear the full range of consequences - immediate and ultimate that follow from particular behavior". Nicolaus is, however, quite accurate when he interprets my response to his earlier paper as reflecting a "deep concern for the problem of countercontrol". Again, I will attempt to raise these issues.

Scientific technology may, given an unlimited amount of time and societal resources, possess the ability to make clear many of the consequences resulting from particular behavior. At some point, however, governments must appraise existing information and plan a course of action based on that data. Often the current state of knowledge does not lead to a clear. empirically based decision: evidence is either contradictory or inaccessible. In such cases (I would propose that these are the vast majority) I question the assumption that behavioral scientists, by virtue of their discipline, are more capable of making socially appropriate decisions than are their fellow citizens.

I am more deeply troubled, however, by the issue of corruption in government. This, in other words, is the issue of counter-control. The solutions offered by both Nicolaus and
Skinner are inadequate. They offer size and communal ownership as the two major instruments of community control over governors. The social control gained by having governors live in close proximity with the governed is, as I see it. the major benefit of small social units. Communal ownership and equitable distribution of the community's resources provides a major disincentive for corruption of the leadership.

Are size and communal ownership sufficient controls on governors? They may be components of effective counter-control. but 1 do not believe they are sufficient. One need only look to. Jonestown for an example of a small, communal society gone astray.

It is. as Nicclaus has stated. time for us to move beyond our armchairs. Talk of pilot communities isolated for generations from the rest of the world is just that - armchair speculation. Our work. as I previously stated. should be directed towards an analysis of our existing environment: strengthening those institutions which enhance behavior directed towards the "greatest good for the greatest number" and creating new model institutions. Many may disagree but I believe a number of these institutions currently exist and present the most concrete opportunity for behaviorists interested in social change to have an impact on the direction of our society. 